\title{
Default Vegetarianism and Veganism
}

\author{
Timothy Perrine ${ }^{1}[$ (1)
}

Accepted: 9 March 2021 / Published online: 1 April 2021

(c) The Author(s), under exclusive licence to Springer Nature B.V. 2021

\begin{abstract}
This paper describes a pair of dietary practices I label default vegetarianism and default veganism. The basic idea is that one adopts a default of adhering to vegetarian and vegan diets, with periodic exceptions. While I do not exhaustively defend either of these dietary practices as morally required, I do suggest that they are more promising than other dietary practices that are normally discussed like strict veganism and vegetarianism. For they may do a better job of striking a balance between normative concerns about contemporary farming practices and competing considerations of life. Additionally, I argue that framing discussions in terms of defaults is useful for various reasons: it helps organize agreements and disagreements, it more accurately reflects the way people conceptualize their dietary practices, and it presents a more dialectically effective view.
\end{abstract}

Keywords Animal ethics · Default vegetarianism - Default veganism - Clean hands · Contemporary farming practices

\section{Introduction}

A dietary practice includes both a diet - a set of purchasing and consuming behaviors - a cluster of normative attitudes about that diet - the desirability, permissibility, attractiveness, etc. of that diet-and beliefs about how to conform to the diet. In the past several decades, more information has come to light about the costs of standard diets on animal welfare, the environment, and farming communities. In light of this information, many philosophers have focused on the normative status of various dietary practices - to which degree certain dietary practices actually are good or bad, permissible or impermissible, virtuous or vicious, etc.

However, some might be dissatisfied with the range of dietary practices that are discussed. The dietary practices discussed in ordinary life frequently lie on the ends of an extreme-either entirely unrestrictive in what people purchase and consume

Timothy Perrine

timperrine@gmail.com

1 School of Philosophy, Wuhan University, Wuhan, China 
or quite restrictive and prohibitive. Philosophers do discuss intermediate dietary practices. But normally those dietary practices are unrealistic for most consumers in developed countries.

The overall aim of this paper is to describe a pair of dietary practices that are more moderate and realistic. I call them default vegetarianism and default veganism. The basic idea is that one has a certain diet-vegetarian diet and vegan diet respectively_as a "default" or "normal" practice for specific reasons that normally hold. My aim here is not to argue that consumers are required to adopt these dietary practices, though that would probably be good. Nonetheless, it is still useful to describe these practices because they balance various normative concerns; they help organize agreements and disagreements; they may more accurately reflect the way people conceptualize their own dietary practices; and they may be more dialectically effective and efficient in philosophical conversation.

In the "Dietary Practices: Standard Options and Dissatisfaction" section, I briefly defend dissatisfaction with the range of dietary practices normally discussed, indicating that discussion of a moderate but realistic dietary practice is desirable. In the "Defaults" section, I describe the general idea of a "default" as a kind of practice. In the "Default Vegetarianism and Veganism" section, I use the idea of a default to articulate the dietary practices default vegetarianism and default veganism. I give some possible motives for adhering to these practices as well as illustrating them. In the "Comparisons" section, I briefly compare these dietary practices to others. I argue that they are not clearly defective in normative status. I compare them to a few other dietary practices and show how they may help illuminate some current philosophical discussions. Finally, in the "From Clean Hands to Defaults" section, I address a challenge from some who will propose a "clean hands" approach to these issues. I suggest that the quest for "clean hands" is mythic and needs to be replaced with some more complicated cluster of attitudes and practices. Default practices are one example of a more complicated approach.

\section{Dietary Practices: Standard Options and Dissatisfaction}

A dietary practice, as I'll use the phrase, has several components. First, a diet, that is, a cluster of behaviors about how people purchase and consume dietary products. ${ }^{1}$ Second, attitudes about the diet such as its value, desirability, utility, etc. Third, beliefs linking those attitudes to the behavior. These beliefs will include what sort of behaviors conform to the diet. These beliefs include beliefs about what behaviors conform to the diet—what constitutes "following" it—as well as a person's ability to conform to that diet. (And, of course, such beliefs may not be entirely accurate.) ${ }^{2}$

\footnotetext{
${ }^{1}$ I'll bring together both purchasing and consuming, since the vast majority of the time for the vast majority of people these coincide.

${ }^{2}$ For my discussion here, I'm mostly focused on dietary practices that are stable for a person. I'll have little to say about dietary interventions, like those aimed to reduce the onset or severity of a disease. I will not discuss the issue of adherence to a dietary intervention. A variety of factors can change or reinforce a dietary practice. See Asp (1999) and McCann and Bovbjerg (2009) for an overview of fac-
} 
In virtue of both adherence and discussion among people in developed countries, there are three major dietary practices. ${ }^{3}$ First, permissible omnivorism a diet where one consumes animal products of various kinds; attitudes that there is nothing impermissible, bad, or otherwise undesirable about such a diet; and beliefs about how to conform to the diet. Second, strict vegetarianism a diet where one strictly does not consume meat products but periodically consumes non-meat animal products; attitudes that this diet is obligatory, good, or otherwise desirable; and beliefs about how to conform to the diet. Finally, strict veganism a diet where one strictly does not consume animal products; attitudes that this diet is obligatory, good, or otherwise desirable; and beliefs about how to conform to that diet.

The term 'permissible' in 'permissible omnivorism' refers to the attitudes that are part of the dietary practice-adherents to this dietary practice maintain that it is permissible to eat in the way they do. Likewise, the term 'strict' in 'strict vegetarianism' and 'strict veganism' refer to the attitudes that are part of the dietary practices-adherents to the dietary practice maintain that they must eat in the way they do. But of course, adherents to these diets may be wrong in their attitudes. It is thus worthwhile to explore potential normative bases for these dietary practices. ${ }^{4}$

Many philosophers have focused on potential normative bases for these dietary practices. A normative basis might consist of a singular normative principle or a larger encompassing normative framework. For instance, starting in the 1970s and 1980s, Peter Singer and Tom Regan utilized different normative frameworks - utilitarianism and a rights-based framework respectively - to evaluate these dietary practices. More recently, Hursthouse (2011) and Abbate (2014) have utilized a virtue theoretic framework. And DeGrazia (2009) utilizes a singular normative principle that any adequate normative framework should accept. And, of course, one might find other frameworks as well. ${ }^{5}$ Presumably different authors use different normative frameworks because they antecedently think that different normative frameworks are more plausible than others.

Philosophers do not exclusively discuss those dietary practices. Sometimes they discuss others as well. But normally the other dietary practices are created by arguing that some philosophical basis does not support one of those three dietary practices but some other dietary practice instead. For instance, in a well-known article, Steven Davis (2003) argues that a principle in Regan's work-what he calls the

\footnotetext{
Footnote 2 (continued)

tors; Nestle (2007) is an influential discussion of the historical role of the food-industry. Finally, note that positive attitudes directed towards a diet do not necessarily imply adherence to that diet. In a study among Irish consumers, Roddy, Cowan, and Hutchinson (1996: 50-57) found that a non-trivial percentage of shoppers reported positive attitudes towards organic produce while nonetheless purchasing it less than others with less positive attitudes.

3 Of course, these aren't the only ones. I discuss a few more in the "Comparisons" section below.

4 The strictness here does not refer to difficulties of access to vegetarian or vegan food in a population. Perhaps in some cultures where vegetarianism is more accepted-India comes to mind-adherence may be easier. And perhaps in some places_- "food deserts" come to mind-adherence to such dietary practices would be much harder. (Thanks to a reviewer for having me clarify this point.).

5 Such as the capabilities approach (cf. Nussbaum (2006)), "relational" frameworks (cf. Palmer (2010)) and ecofeminism (cf. Warren (2000), Gaard (2017)), to name a few more.
} 
"Least Harm" principle_-does not actually support strict vegetarianism or strict veganism. Instead, it supports a dietary practice where people purchase and consume animal products that originate in pasture-forage sources. Similarly, Fischer (2016) argues that certain "precautionary" principles do not support strict veganism but rather a diet including insect consumption. MacClellan (2013) takes seriously the idea that utilitarian considerations might imply that we kill and consume blue whales. Brucker (2016) argues that standard arguments for vegetarianism might imply that we ought to eat vegetables and roadkill.

However, at this point in time, some dissatisfaction might set in - at least it does for me. The dissatisfaction concerns the topic of discussion, the particular dietary practices discussed. On the one hand, given contemporary farming practices, permissive omnivorism seems too good to be true. And while we might dispute what different philosophical bases may say of that dietary practice, we should be confident that virtually none give it a full-throated endorsement. On the other hand, strict vegetarianism and veganism seem too normatively inflexible and rigid, too extreme in the opposite direction. Given the complexities of life, we might reasonably expect that deviations - even routine deviations - from a vegetarian or vegan diet are permissible, even for consumers in a developed country. Life is too complicated to announce the contrary, prior to examining all concrete situations.

This dissatisfaction suggests that it is worth discussing other types of dietary practices. However, when we turn to the other dietary practices discussed by philosophers, my disappointment remains. For those alternative dietary practices are frequently impractical or distasteful. For instance, even if Davis is correct that Regan's "Least Harm" principle would support a food production system of animal meat heavily composed of pasture-forage sources, most consumers don't have a choice to purchase food from such a food production system. Additionally, many of us couldn't stomach roadkill. And while I can periodically find insects at my open-air market, I don't think it is particularly representative of food available to most consumers. And I certainly have never found blue whale meat there!

It is not hard to see why these dietary practices are not very realistic. They were not created by thinking through the situations of consumers. Rather, they were created by considering detailed or specific cases where philosophical bases would fail to support one of the three main dietary practices. Otherwise put, they were created by considering potential—but not necessarily common-situations instead of focusing on common situations for consumers.

My approach here will be different. I start by describing a pair of dietary practices that I think are realistic for many consumers. I will briefly argue that these dietary practices are intermediate between permissive omnivorism on the one hand and strict vegetarianism and veganism on the other. Describing such intermediate practices does not guarantee that people-individually or collectively-ought to adopt them. And it is entirely possible that some will still be dissatisfied with some intermediate dietary practices. However, describing intermediate dietary practices may help expand the choice of options under discussion for a fuller comparison of their normative status. 


\section{Defaults}

The dietary practices I will describe are a kind of "default" practice. So, I will begin with a brief discussion of defaults. Nowadays the word 'default' is associated with technology-coffee machines, phones, apps, etc. have "default" settings. These default setting are normally automatic, preselected, or otherwise the standard setting. However, they can be changed when needed. They are not immovable or fixed.

Similarly, I have in mind a "default" practice for a person. Again, a practice will include at least three elements. First, a behavioral component of performing kinds of actions (or omissions). Second, attitudes about the normative status of those actions - the degree to which those actions are good, bad, required, permitted, pleasant, gross, etc. Third, beliefs about what actions conform to the relevant behavior and beliefs about the person's ability to conform to the behavioral component. In describing defaults, I don't aim to provide a necessary or sufficient condition but to identify a kind of practice that I hope readers are familiar with. To that end, I begin by contrasting defaults with what I'll call "mere habits," "internalized constraints," and "intentional flexibility."

A mere habit involves frequently or habitually performing certain actions where either one does not realize one is performing the action or has not developed extensive attitudes about the normative statue of such actions. When people have a mere habit they routinely and automatically perform some action, but without giving that action or type of action much thought. For instance, people who have mere habits need not have any beliefs about what it takes to conform to that habit.

An internalized constraint is a habit to always or almost always perform an action combined with attitudes that performing this action is right, correct, good, etc. For instance, some people-normally those who worked in the service industry-have an internalized constraint to always leave a good tip when they eat at a restaurant. Some parents have an internalized constraint to never resort to any kind of physical violence to reprimand their children.

Intentional flexibility is where one engages in a range of alternative actions with attitudes that there is not necessarily any strong reason for preferring one of the alternatives to another. For instance, a person might frequent a restaurant but intentionally choose a new dish each time just to try something different. A couple might vacation at different spots each year simply to explore different places. But they may not regard there as being a conclusive reason for choosing any particular spot they travel to. Whimsy is a frequent example of intentional flexibility.

As I'll understand them, defaults are distinct from each of these. Unlike a mere habit, a default to act in a certain way involves some attitudes about performing those kinds of actions. Both internalized constraints and intentional flexibility involve attitudes about one's action. But defaults are distinct from both. Unlike an internalized constraint, a default does not involve a commitment to always, or almost always, perform a particular kind of action. However, unlike intentional 
flexibility, a default does involve performing a certain kind of action most of the time-having a standard or normal action one performs.

Let's turn to a simple example. I walk to work. I take a specific route through a park. I normally take this route. I walk this way because it is efficient and pleasant. There are more routes to my office, but they are either less efficient or less pleasant. Walking this route is not a mere habit. I have thought about it and tested several other routes. Walking this route is not a case of intentional flexibility. After all, I normally walk this route and think there are good reasons for choosing this route over others. Walking this route is not an internalized constraint. Sometimes I do deviate from it to purchase flowers or stop by the bank on my way to work.

Defaults have exceptions. When one has a default to act in certain ways, one has attitudes about the normative status of those actions. Those attitudes help determine what one regards as exceptions to acting in this way. Most exceptions will involve one or two components: a belief that either (i) the considerations in favor of the default action are absent or (ii) other considerations are present that outweigh the considerations in favor of the default. Of course, these beliefs may not be accurate. Beliefs about how to conform to certain behavioral norms are not infallibly true.

To illustrate, my current path to my office is both convenient and pleasant. But on days where I need to go to the bank, the path is inconvenient. In that situation, one of the considerations in favor of the default action is outweighed. But there can also be situations where the considerations in favor of taking the path are absent altogether. If they temporally close down a portion of the path for noxious construction, then it will be neither pleasant nor convenient. During such a time, my alternative route will be an exception to the default route.

Exceptions to defaults further help distinguish defaults from internalized constraints and intentional flexibility. If a person has an internalized constraint to perform a certain action, they might concede that they can entertain a possible scenario where they would not want to perform that action. (After all, philosophers and Hollywood producers are quite clever in coming up with scenarios.) But they might insist that such scenarios are not realistic and would not occur in their own life and can thus be ignored. For such a person, there are no realistic exceptions to their internalized constraint. By contrast, if a person is intentionally flexible when choosing between certain actions, the idea of an exception does not apply at all. For there is no normal, baseline, or default to be an exception to.

When an agent has a default to engage in a certain set of behavior, there are normally considerations she could provide that at least partly explain why she acts in those ways. But those considerations do not normally occurrently motivate her when she engages in those behaviors. When I walk to work, I do not first begin by rehashing various considerations. I merely begin walking. Of course, I could provide those considerations when prompted, or when a possible exception might arise. But normally the considerations agents would cite for their defaults play a causal role in generating their defaults and not necessarily maintaining them at every junction.

Finally, notice that two people might engage in the same behavior but have different defaults. For their attitudes and beliefs about that behavior may differ; thus, what they recognize as actual or potential exceptions to that default may differ. For instance, two people might have the same default of not working on a Sunday. 
But one person has religious reasons, the other merely to relax and catch up on his favorite sports teams.

\section{Default Vegetarianism and Veganism}

Having characterized defaults, I turn to dietary practices. First, default vegetarianism is a dietary practice whereby one engages in a vegetarian diet as a default. Thus, engaging in a vegetarian diet is the standard, normal, or default action(s) one performs. Additionally, one has attitudes that the diet is good, desirable, worthwhile, etc. and beliefs about how to conform to this diet. Second, default veganism is a dietary practice whereby one engages in a vegan diet as a default. Thus, engaging in a vegan diet is the standard, normal, or default action(s) one performs. Additionally, one has attitudes that the diet is good, desirable, worthwhile, etc. and beliefs about how to conform to this diet.

Both dietary practices include attitudes about the diets that motivate people to adhere to that dietary practice. People adopt vegetarian or vegan diets on the basis of various concerns. However, the three main concerns involve animal welfare, the environment, and health (see Fox and Ward (2008), Ruby (2012), Janssen et. al. (2016)). As these concerns are well-known, I'll just briefly describe each with a sampling of relevant citations.

\section{Animal Welfare Concerns}

Animals raised for slaughter normally experience a great deal of suffering. Some animals have parts of their bodies removed or trimmed-e.g. beaks in chickens, tails in pigs - to deter aggressive interactions with other animals. Almost all are kept in restricted and overcrowded places. They are unable to play or socialize as normal. Sometimes the animals are overfed to the point of immobility. And slaughter is done with an eye towards efficiency of time management and meat production instead of pain reduction. Egg laying chickens and diary cows are not raised for slaughterthough they normally are slaughtered-but have similarly problematic treatments. They too are kept in confined spaces, unable to move, play, or socialize as normal. The vast majority of these animals have lives that are not worth living. And there are many of them. In the US in 2018 alone, 32 million cattle were slaughtered; 123 million pigs were slaughtered; 7 billion chickens were slaughtered; and there were over 9 million milk cows and 390 million egg laying chickens. (For more information and details, see the following from which I compiled this information: USDA (2017, 2018a, b, c), Singer (2002), Rachels (2011), Gruen (2011).) 


\section{Environmental Concerns}

In general, vegetarian and vegan sources of protein utilize fewer environmental resources than meat-sources of protein especially beef. They utilize proportionally less water, energy, fertilizer, and pesticides. Vegetarian and vegan diets produce less emissions. Vegetarians and vegans tend to advocate for organic and more traditional types of farming that would also be better environmentally. (For more information and details, see the following from which I compiled this information, see Reijnders and Soret (2003), Pimentel (2005), Baroni et. al. (2007), Marlow et al (2009), Tilman and Clark (2014), Clark and Tilman (2014), Scarborough et al. (2014), Drew et al. (2020).)

\section{Health Concerns}

Well-planned vegetarian and vegan diets are healthy. Though vegetarian and vegan diets can be low in zinc, calcium and B-12, with proper planning and supplementation, such diets are healthy. They are certainly healthier than a common diet that consumes large amounts of processed red meat, saturated fats, and refined sugars. Vegetarians and vegans are observed to have lower BMIs, lower rates of type II diabetes, and lower rates of various heart diseases. (For more information and details, see the following from which I compiled this information: ADA and DC (2003), Key, Appleby, Rosell (2006), Craig (2009), Barnard (2009), and Le and Sabaté (2014). $)^{6}$

Default vegetarianism and veganism are distinct from strict vegetarianism and veganism. The key difference here are attitudes about exceptions. Many adherents to strict vegetarianism and veganism have an internalized constraint to adhere to a vegetarian or vegan diet. While they might admit that there could be permissible exceptions to those diets, they tend to regard them as unrealistic and unlikely to occur. By contrast, an adherent to one of the default diets may regard permissible exceptions to be realistic, perhaps common and routine. An adherent to one of the default diets might periodically consume animal or meat products when they regard the considerations as either absent or outweighed.

\footnotetext{
${ }^{6}$ Some vegetarians and vegans might claim, more strongly, that diets that incorporate meat could not be very healthy. I am doubtful this is the case. Part of the problem of fully testing this claim is that high consumption of meat, especially processed meat, correlates with additional unhealthy dietary habits (see Fogelholm et al. (2015), Grosso et al (2017)). Indeed, it is entirely possible that a well-planned lowintake meat diet is as healthy as a well-planned vegetarian or vegan diet, though of course there might be slightly different benefits to each—see McEvoy, Temple and Woodside (2012). Likewise, when it comes to environmental impacts, different products - and perhaps the same product in different regions-may have different effects. For instance, in some places, it may be that fish/sea food products have less carbon emission than tofu, as suggested by Kortetmäki and Oksanen (Forthcoming: 4 fn. 16).
} 
Some illustrations. A person might be motivated to adhere to default veganism on the basis of animal welfare concerns. However, they might regard those concerns as absent when it comes to an exception of eating eggs produced by chickens they raise in their backyard. A person might be motivated to adopt default veganism for environmental reasons. Nonetheless, in consultation with a doctor, they might opt to incorporate small portions (e.g. $100 \mathrm{~g}$ ) of lean meat in their diet once or twice a week to ensure that they are getting adequate nutrition for their long-term health. For such a person the environmental concerns are not absent in these exceptions; they are outweighed. A person might adopt default vegetarianism and yet have as an exception the consumption of meat-products as part of a traditional, cultural celebration. In such a case, the health concerns may be outweighed by participation in the cultural celebration or absent if the consumption is minimal enough.

These examples illustrate that default vegetarianism and veganism are better thought of as families of dietary practices. Different motivations, reasons, and attitudes will lead to different exceptions. Nonetheless, what would unite different versions of default vegetarianism and veganism is that there is a default, normal, or base line diet of vegetarianism or veganism. In this way, they are different from both permissive omnivorism and strict vegetarianism or veganism.

\section{Comparisons}

This section briefly compares default vegetarianism and default veganism to other dietary practices. My overall aim is to encourage more explicit discussion of these dietary practices. To that end, in the "Revisiting Dissatisfaction" subsection, I show that these dietary practices are not obviously normatively defective; in the "Additional Diets" subsection, I consider a few other dietary practices but suggest that they are not ideal objects of discussion; finally, in the "Comparisons to Other Philosophical Works" subsection, I suggest that other philosophers may have been advocating for something like these dietary practices, but it would be superior to describe them more fully as I have done.

\section{Revisiting Dissatisfaction}

Some, such as myself, are dissatisfied with discussion of the three major dietary practices. I have suggested we look at intermediate dietary practices that are more realistic than those sometimes discussed by philosophers. But if those intermediate dietary practices are clearly normatively defective-having nothing to say for them-then there is little point in discussing them. I will briefly argue that the dietary practices default vegetarianism and veganism are not obviously normatively defective. Further, they are not obviously defective in virtue of threading the needle between the three major dietary practices.

First, a lot of ink has been spilled on the permissibility of acting in accordance with permissive omnivorism. But I will focus on a comparison of attitudes. Adherents to default vegetarianism or veganism are more likely to have compassionate 
attitudes vis-à-vis contemporary farming practices than adherents to permissive omnivorism. Many animals used in contemporary farming practices suffer greatly. The appropriate or correct attitudes in response to their suffering are disappointment, frustration, anger, sadness, etc. Adherents to default vegetarianism or veganism who adhere to them for animal welfare concerns are more likely to have these attitudes than adherents to permissive omnivorism. Further, on my view, having an appropriate or correct attitude can be valuable - a good thing. So adherents to default vegetarianism or veganism are more likely to have valuable attitudes than adherents to permissive omnivorism. Additionally, having attitudes of disappointment, frustration, anger, sadness, etc. are the compassionate attitudes to have in response to animal suffering. They are the attitudes a compassionate person would have. Thus, adherents to default vegetarianism or veganism are also more likely to have compassionate attitudes regarding animal suffering than adherents to permissive omnivorism. (See Perrine (2020) for additional discussion.)

Second, adherence to strict vegetarianism or strict veganism may interfere with other goods in a way that adherence to default vegetarianism or veganism need not. Perhaps the most common kind of cases involves situations of poverty and health but there may be others. Simply put, for some people, incorporating some amount of meat and/or animal product in their diet might be necessary given their financial resources, social situation, or desire for long term health. As noted earlier, a wellplanned vegetarian or vegan diet can be just as healthy as one incorporating meat and/or animal products. However, a well-planned diet normally requires advance thought, knowledge of what to eat, access to sufficient vegetarian and vegan sources of food, and financial means to acquire those sources of food. These are not always available. To take an example ready at hand, a single mother working two jobs might simply not have the time, energy, or resources to always prepare vegetarian or vegan meals. Cases like these do occur and they include other important features of life that can periodically outweigh the considerations in favor of a vegetarian or vegan diet. In such situations, adherence to strict vegetarianism or veganism would have a person compromising their finances or long-term health. But adherence to default vegetarianism or veganism allows exceptions, including perhaps exceptions for cases like these. ${ }^{7}$

Some adherents to strict vegetarianism or veganism may accuse me of targeting a straw man. Some adherents do allow for what could be described as exceptions. If one is stranded on a desert island, perhaps it is permissible to kill and eat wild fowl. If one is forced to choose between saving a human life-say, a close family member-or consuming meat, adherents may urge one to consume meat. Or if one belongs to a rural family in an underdeveloped country-or a harsh winter climate with little vegetation-it could be permissible to kill and eat the family hog or dog.

However, the kind of exceptions that adherences to strict vegetarianism or veganism normally allow for are unrealistic for the vast majority of people in developed countries. Many of the exceptions they allow for are ones that would not, and could not be reasonably expected to, occur to the vast majority of people. However, the

\footnotetext{
${ }^{7}$ For a narrative approach to some of these issues, see Brueck (2017).
} 
kind of dissatisfaction I have, and I believe others have, are not based in such unrealistic scenarios but the lives (and plights) of people even in developed countries.

\section{Additional Diets}

In the "Dietary Practices: Standard Options and Dissatisfaction" section, I focused on three major dietary practices: permissive omnivorism, strict vegetarianism, and strict veganism. I focused on them because they are the most prominent in virtue of discussion and adherence. But there are additional diets. These include the lactovegetarian diet which is like strict veganism except one consumes milk products. The ovo-lactovegetarian diet which is like lactovegetarian diet except one also consumes egg products. The pescatarian diet which is like strict vegetarianism except one consumes fish and seafood. Finally, there is the so-called flexitarian diet which has been described as a mostly vegetarian diet with periodic consumption of meat. Despite the fact that these diets have enough social influence to have well-known names, they are not normally discussed by philosophers (with Hare's (1993) representing a noteworthy exception).

However, if one's concerns about dietary practices are normative concerns, then these dietary practices are not ideal objects of discussion. For the categories we use to distinguish between these dietary practices are categories that come from the way food items are frequently packaged, sold, or advertised. (E.g., the categories of milk or diary product, egg product, seafood.) But there is no reason to assume that the categories used to group the way food items are packaged, sold or advertised will line up, even approximately, with the normative concerns that may inform one's dietary practices.

Consider the pescatarian diet. The pescatarian diet is like strict vegetarianism except one consumes fish and seafood. But the category of fish and seafood includes animals as diverse as sponges, scallops, oysters, shrimp, eels, fish (fresh and salt water), and squids. The degree to which each of these animals can suffer greatly varies; and the environmental costs of rearing, catching, and killing these animals also greatly varies (and varies by region). It would be deeply surprising if the normative concerns I considered in "Default Vegetarianism and Veganism" section lined up with this category.

However, the flexitarian diet may be an exception here. But it is notably different from some of these other diets in including an idea of being "flexible" in a way they don't. In fact, the flexitarian diet is perhaps closest to what I've described as default vegetarianism (though perhaps not similar to default veganism). However, the flexitarian diet is normally described primarily in terms of its health benefits and its ability for weight loss. (Many books about the flexitarian diet that I found were actual health/wellness cookbooks or diet plans.) Obviously, agents may adopt default vegetarianism or veganism on the basis of concerns other than health or weight loss. 


\section{Comparisons to Other Philosophical Works}

Some philosophers do not offer philosophical bases for the three main dietary practices described in the "Dietary Practices: Standard Options and Dissatisfaction" section. Indeed, they seem to allow for exceptions to vegetarian and vegan diets in a similar way to what I've described. For instance, Singer once wrote "Whether we ought to be vegetarians depends on a lot of facts about the situation in which we find ourselves" (1980: 327). And he allows when there is a "irreconcilable conflict" between the "basic survival needs" of humans and some non-human animals, it could be permissible to consume animal products (2011: 122). And in some interviews Singer describes himself as a "flexible vegan." Singer's position is similar, if not the same, as what I've described. ${ }^{8}$

It is perhaps unsurprising that Singer describes his position that way, given his utilitarianism. However, some non-utilitarians may also embrace similar views. Hursthouse (2011: 131) claims that from the perspective of virtue ethics it would not be reasonable to conclude that agents ought never eat meat or fish; after all, a person "stranded in the Australian outback" who killed and ate a rabbit need not be acting in callous and self-indulgent ways. And even authors who do not explicitly address the issue leave open the possibility of exceptions. For instance, DeGrazia advocates for the following rule: "Make every reasonable effort not to provide financial support to institutions or practices that cause extensive, unnecessary harm" (2009: 148, 159, 160). DeGrazia does not spent extensive time discussing what "reasonable effort" is. But presumably this qualification is to allow that in some situations the effort would not be reasonable and those might be permissible exceptions. One can find additional authors who, after arguing for positions that look a lot like strict vegetarianism or veganism end up gesturing towards possible exceptions at the end of their papers (e.g., Curnutt (1997), Hooley and Nobis (2016)). ${ }^{9}$

As an exegetical matter, it is not clear to me that all of these authors are defending default vegetarianism or veganism. Some of them might be closer to defending strict vegetarianism or veganism, since the exceptions they might allow are simply unrealistic for most people in developed countries. But let's simply assume, as an exegetical matter, that they are. There are still several reasons why it is useful to articulate and describe these dietary practices as I have.

First, describing the dietary practices is useful for understanding agreement and disagreement between authors that might otherwise appear quite disparate. If many philosophers are actually defending something like default vegetarianism or veganism, then there is actually a great deal of agreement between philosophers. This agreement might be overlooked if we focus — as we philosophers tend to do- on the different philosophical bases used in argumentation.

\footnotetext{
${ }^{8}$ I do prefer my label over Singer's though. 'Flexible' may have connotation of being unprincipled or wishy-washy that I would prefer to avoid. But this is a small point.

9 One more recent author who is sensitive to these issues is McPherson (2016, 2018). He explicitly defends, from the beginning, a view on which it is "typically" wrong to use animal products. He does not claim that it is always wrong, nor is this a caveat added at the end. (Thanks to a reviewer for drawing my attention to this work.).
} 
Additionally, if many philosophers are actually defending something like default vegetarianism or veganism, then this also helps conceptualize disagreements. For disagreements would be over what the morally permissible exceptions are. To illustrate, some people are concerned about causally contributing to contemporary farming practices; others are concerned about being complicit in contemporary farming practices. Some people are concerned about animal suffering; others are concerned about animal slaughter. These different concerns give rise to different views about permissible exceptions. Thus, disagreements between people's views are not disagreements over whether or not one's dietary practice should exhibit a default structure but disagreements over the permissible exceptions to the defaults. If this is right, then for most consumers in developed countries the discussions to be had are over permissible exceptions, not the status of defaults. ${ }^{10}$

Second, philosophers sometimes neglect the way that agents conceptualize their own actions, focusing instead on different normative bases or justifications for actions. That is not necessarily a criticism of the goals of philosophers. It is a worthwhile task to provide a normative basis for a set of actions-or determine that there is not one. But without a discussion of how agents can or should conceptualize their own actions, philosophical discussion is incomplete. Such discussion is especially important for dietary practices since the choice to adhere to a dietary practice is psychologically serious in terms of frequency and depth. Consumers make food choices everyday and multiple times a day. These are not rare or unusual choices. Further, adhering to a certain kind of diet often times becomes part of a person's practical identity, who they are and self-identify as (see Bisogni (2002)). Indeed, being vegetarian — and especially vegan — are so central to some people's lives that it has become an internet meme. ${ }^{11}$

Philosophical discussion that neglects how people conceptualize their own dietary practices are likely to be incomplete or even inaccurate. I'll briefly illustrate this point with Hursthouse (2011). Hursthouse describes her own desire for eating meat as "greedy" and "self-indulgent" (2011: 130). Since the virtuous person does not engage in greedy or self-indulgent actions, on her view, this is a reason for not eating meat. Hurthouse's description suggests a model on which vegetarians conceptualize the choice of eating meat primarily in terms of being "greedy" and "self-indulgent."

But many vegetarians or vegans do not conceptualize their dietary choices in this way. First, even if eating meat is greedy and self-indulgent, this does not highlight the salient facts about eating meat for many vegetarians and vegans. After all, many

\footnotetext{
10 A more complicated illustration. Belshaw (2016: 9 fn. 1) complains that DeGrazia (2009) claims to be giving an argument for vegetarianism and yet has "no position" on fish and invertebrate seafood. Belshaw quips that "this is tantamount to having no position on vegetarianism." However, DeGrazia's argument is based upon animal sentience. Using the terminology here, we could understand DeGrazia as arguing for default vegetarianism where the default is based upon concerns of animal welfare grounded in sentience. Where there is unclarity about animal sentience-as DeGrazia claims there might be in fish-the default may or may not apply. Belshaw might claim this is still "no position on vegetarianism" but, once we start using my terminology, that claim is misleading at best.

11 E.g., "List of Mythical Creatures: Swampman, Vampires, Vegans Who Don't Tell You They Are Vegan Within 5 minutes, Wendigos, Chupacabra, etc.".
} 
actions are greedy and self-indulgent - such as spending the night watching tv and eating a pint of (perhaps vegan) ice cream instead of doing necessary work. But clearly to many vegetarians and vegans there are important differences between that act and eating meat. Second, even if vegetarians or vegans are motivated by considerations of greed and self-indulgence, the structure of their motivation will be something like a default. For vegetarians and vegans opt out of meat frequentlynormally at every meal. Considerations of greed and self-indulgence do not occurrently motivate them at each meal. (Vegetarians don't normally open a menu at a restaurant, consider the steak, and then set aside such a choice as greedy and selfindulgent-it normally gets eliminated as a potential option from the beginning.) Rather, at best, such considerations would help generate a practice like a default that creates a baseline of options. None of these points suggest that Hursthouse has failed to identify a sufficient philosophical basis for a dietary practice like default vegetarianism. But it is to suggest that her discussion is incomplete regarding how many people might actually conceptualize their dietary practices.

Finally, some philosophers mention the possibility of permissible exceptions to their recommended dietary practices almost as if it were an afterthought. Presumably they include such exceptions because they are concerned about the moral complexities of life. But if they really are advocating for something like default vegetarianism or veganism, it would be clearer to acknowledge the possibility of such exceptions from the beginning and frame discussion in terms of defaults.

Indeed, such an acknowledgement might even be dialectically effective and efficient. A common "undergraduate reaction" to arguments for strict veganism is that if anyone is required to adhere to strict veganism, then everyone ought to; but not everyone ought to adhere to strict veganism; and thus no one is required to. Examples are then provided of people who are not required to adhere to strict veganism. (Indeed, the most vigorous defenses of non-vegan nutritional habits for pregnant mothers and newly born children can be found in 21-year-old male students who have a zealous love of the cheap wing night at the nearby bar.) Obviously, this objection is no good-from the mere fact that some people ought to do something it doesn't follow that everyone ought to do it. But positions like default vegetarianism or veganism do not even give a foothold to this kind of objection since they explicitly allow that there may be exceptions to those dietary practices. (Exceptions that may apply to pregnant mothers, but probably not to 21 year-old, wing loving male students.)

So even if other philosophers have defended something like the dietary practices I have described here, it is still useful to describe them. Describing them helps reveal unity among views that might otherwise be missed; it helps organize disagreements between philosophers; it may more accurately reflect the way people might conceptualize their own dietary practices; and it is a clearer presentation of a view that may be more dialectically effective. 


\section{From Clean Hands to Defaults}

In comparing permissive omnivorism with default vegetarianism and veganism I suggested that the latter might be more compassionate as they are more likely to be accompanied by appropriate and correct attitudes towards the suffering of animals. At this point, I anticipate some adherents to strict veganism will object-if one is motivated by concerns of compassion then how could any diet that includes any animal product be thought of as a compassionate one. Indeed, they might even find the labels I am using-default vegetarianism and default veganism-oxymoronic. This section critically engages with their perspective drawing on some work from Lori Gruen and Robert C. Jones (2016).

Some adherents to strict veganism find themselves morally appalled by the treatment of animals in contemporary farming practices. Indeed, some adherents liken the treatment of animals to the twentieth century holocaust of World War II. As they see it, complete and total prohibition from purchasing and consuming animal products-including adherence to strict veganism - is the moral minimum. Anything short of a "clean hands" approach is unsatisfactory and lacking in compassion. Some adherents to strict veganism might also advocate for additional practices ranging from refusing to eat at meals where animal products are served to some forms of activism (legal or otherwise).

Lori Gruen and Robert C. Jones (2016) call this kind of veganism Identity Veganism. I prefer Purity Veganism. For, as indicated earlier, dietary practices are frequently part of people's identities. What is distinctive about these adherents is not that their dietary practice is part of their identity but that they self-identify with a practice them emphasizes a "pure" lifestyle devoid of the use and consumption of animal products. However, regardless of the label used, clearly there are such people and that they would oppose the dietary practices I have described.

Gruen and Jones (2016: 157-158) plausibly argue that Identity Veganism is too simplistic and ignorant. I'll summarize three reasons. First, as is becoming increasingly well-known since Davis (2003), agricultural processes that produce food for vegetarians or vegans often times cause field deaths of animals. (See Fischer and Lamey (2018) for a recent discussion.) Second, even some products that are vegetarian might have negative environmental impacts such as removing habitats for other animals. ${ }^{12}$ Finally, animal products can find their way into all sorts of products beyond dietary ones. (Their list includes surprising items like plywood, perfume, tennis rackets, and transmission fluid.) Unless you live alone and produce your own goods, the quest for perfectly clean hands is mythic.

Proponents of Identity Veganism may claim that only their lifestyle and dietary practice could be compassionate because only their lifestyle and dietary practice completely abstains from the use and consumption of animal products. But if Gruen and Jones are correct, their lifestyle and dietary practices do not completely abstain. Nor could they completely abstain while remaining in modern society. Thus, we

\footnotetext{
$\overline{12}$ E.g., palm oil production and orangutans (Beech (2019)).
} 
need a different way of thinking about compassion in relation to consumer choices than a "clean hands" model.

Gruen and Jones (2016) suggest an alternative way of thinking that I also think is promising: minimization. If one's consumer choices are inevitably caught up with concerns of animal welfare, then a compassionate response may be one that tries to minimize the ways one is caught up. This minimization may apply across one's consumer choices, not just to one's dietary choices. But if we focus on dietary choices, as I am here, a minimization model fits well with a default practice like default veganism. Specifically, a person concerned about animal welfare may see there being a reason, based in compassion, to avoid purchasing and consuming animal products. However, this reason may not be seen as generating a requirement of clean hands, to always avoid such purchasing and consuming. Rather, it is a reason to avoid purchasing and consuming all else being equal, with an understanding that sometimes all else is not equal. This reason might not apply to each purchase/consumption or may be outweighed by other considerations. In cases where the reason is outweighed, it may be appropriate for agents to have mixed feelings. That is, it may be appropriate that they think that an exception is warranted, yet feeling somewhat sad or disappointed nonetheless.

To be clear, the view I am considering here is more complicated on multiple fronts. It is more complicated philosophically in that it claims that a compassionate response to concerns of animal welfare may not take the form of complete and total prohibition. It is more complicated psychologically for those who adhere to default veganism. But I am proposing that a person could be concerned about animal welfare and even strongly opposed to contemporary farming practices, while still maintaining that it could be periodically acceptable to participate in them by purchasing and consuming their products. Identity Veganism is simpler on both fronts. But if that simpler view is too simplistic, we should consider more complex alternatives.

One might worry that the dietary practices I describe here might encourage a "falling off the wagon" phenomenon where participants may eventually backslide into something like permissive omnivorism. As indicated above (fn. 2), changes and adherence to diets is complex. And, as Ruby (2012: 143) laments, there are less studies on former vegetarians and vegans than is desirable. However, there are some. Barr and Chapman (2002) surveyed and interviewed female vegetarians, former vegetarians, and non-vegetarians. Around $40 \%$ of the survey participants cited general health or nutrient as reasons for abandoning a vegetarian diet. Among those interviewed, concerns about health were a major reason for their dietary shift (2002: 358).

Haverstock and Forgays (2012) surveyed and interviewed "former limiters"people who had adhered to pescatarian, vegetarian, or vegan diets but no longer do. They found that they "did not view their eating pattern as part of their identity, made the transition abruptly, and did not access support through vegetarian groups" (2012:1034). While these surveys are limited in various ways, they do suggest that there is no singular reason or cause for backsliding. So I am not sure there is any reason for thinking that adherence to a default dietary practice would increase the likelihood of backsliding. Indeed, for those people who ultimately abandon strict 
vegetarianism or veganism for health related reasons, a transition to a default diet may be the best choice for them. ${ }^{13}$

Summing up, my overall purpose here is not exhaustive defense. I am not trying to extensively argue that people, individually or collectively, are morally required to adopt default veganism or even default vegetarianism. I have not, for instance, provided a philosophical basis for either of these dietary practices. Instead my overall purpose is to encourage more explicit discussion of them. I have tried to encourage more explicit discussion by suggesting that, in comparison to other dietary practices, they may do a better job of balancing normative concerns about contemporary farming practices with the complexities of life we sometimes face. But a full reckoning will have to wait another day.

Acknowledgements For helpful conversation and feedback, I thank Ben Cross, Spencer Case, and two anonymous reviewers. This paper was written while I was under quarantine during the Covid-19 pandemic. For their companionship, I thank my cat 麻辣 and my friend Harrison with his weekly video chats. Above all, thanks to my kindly coworker and friend 李慧敏 for helping me acquire food.

\section{References}

American Dietetic Association and Dietitians of Canada (2003). "Position of the American Dietetic Association and Dietitians of Canada: Vegetarian Diets." Journal of the American Dietetic Association. 103.6: 748-765

Abbate, C. (2014). Virtues and animals: A minimally decent ethic for practical living in a non-ideal world. Journal of Agricultural and Environmental Ethics, 27(6), 909-929.

Asp, E. (1999). Factors affecting food decisions made by individual consumers. Food Policy, 24, 287-294.

Barnard, N., et al. (2009). Vegetarian and vegan diets in type 2 diabetes management. Nutritional Review., 67(5), 255-263.

Baroni, L., et al. (2007). Evaluating the environmental impact of various dietary patterns combined with different food production systems. European Journal of Clinical Nutrition, 61(2), 279-286.

Barr, S., \& Chapman, G. (2002). Perceptions and practices of self-defined current vegetarian, former vegetarian, and nonvegetarian women. Journal of the American Dietetic Association., 102(3), 354-360.

Beech, Hannah. (2019). "One Causality of the Palm Oil Business." New York Times. https://www. nytimes.com/2019/06/29/world/asia/orangutan-indonesia-palm-oil.html

Belshaw, Christopher. (2016). Meat. In Ben Bramble \& Bob Fischer (Eds.), The moral complexities of eating meat. Oxford: Oxford University Press.

Bisogni, C. A., et al. (2002). Who we are and how we eat: A Qualitative study of identity in food choice. Journal of Nutrition Education and Behavior, 34(3), 128-139.

Brucker, Donald. (2016). Strict vegetarianism is immoral” . In Ben Bramble \& Bob Fischer (Eds.), The moral complexities of eating meat. Oxford: Oxford University Press.

Brueck, Julia Feliz. (2017). Veganism in an oppressive world. Sanctuary Publishing.

\footnotetext{
13 How to understand "falling off the wagon" might be, itself, a complex phenomenon. For instance, Rosenfeld and Tomiyama (2019) found a number of self-identifying vegetarians or vegans who periodically consume meat. One might claim that they are backsliding. Indeed, the authors seem to think this as they describe some of these vegetarians and vegans as being "apparently incongruent" and describe how they "rationalized" their consumption of meat (2019: 5-6). No doubt some of those surveyed hold incongruent attitudes and engaged in rationalization. But some of the reported comments by the self-identifying vegetarians and vegans suggest that they are better understood as engaging in a dietary practice like default vegetarianism or veganism that strict vegetarianism or veganism.
} 
Clark, Michael, \& Tilman, David. (2017). Comparative analysis of environmental impacts of agricultural production systems, agricultural input efficiency, and food choice. Environmental Research Letters, 12(6), 064016.

Craig, W. (2009). Health effects of vegan diets. American Journal of Clinical Nutrition, 89, $1627 \mathrm{~S}-\mathrm{S} 1633$.

Curnutt, J. (1997). A new argument for vegetarianism. Journal of Social Philosophy, 28(3), 153-172.

Davis, S. (2003). The least harm principle may require that humans consume a diet containing large herbivores, not a vegan diet. Journal of Agricultural and Environmental Ethics., 16, 387-394.

DeGrazia, D. (2009). Moral vegetarianism from a very broad basis. Journal of Moral Philosophy, 6, $143-165$.

Jonathan, D., et al. (2020). Healthy and climate-friendly eating patterns in the New Zealand context. Environmental Health Perspectives, 128(1), 1-13.

Fischer, B. (2016). Bugging the strict vegan. Journal of Agriculture and Environmental Ethics, 29, 255-263.

Fischer, B., \& Lamey, A. (2018). Field deaths in plant agriculture. Journal of Agricultural and Environmental Ethics, 31, 409-428.

Fogelholm, M., Kanerva, N., \& Männisto, S. (2015). Association between red and processed meat consumption and chronic diseases. European Journal of Clinical Nutrition., 69, 1060-1065.

Fox, N., \& Ward, K. (2008). You are what you eat? Vegetarianism, health, and identity. Social, Science, and Medicine., 66(12), 2585-2595.

Gaard, G. (2017). Critical ecofeminism. Lexington Books.

Grosso, G., et al. (2017). Health risk factors associated with meat, fruit, and vegetable consumption in cohort studies: A comprehensive meta-analysis. PLOS ONE, 12(8), 1-21.

Gruen, L. (2011). Ethics and animals. Cambridge University Press.

Gruen, Lori, \& Jones, Robert C. (2016). Veganism as an aspiration”. In Ben Bramble \& Bob Fischer (Eds.), The moral complexities of eating meat. Oxford: Oxford University Press.

Hare, R. M. (1993). Why i am only a demi-vegetarian.” in his essays on bioethics. Oxford: Clarendon Press.

Haverstock, K., \& Forgays, D. K. (2012). To eat or not to eat. A comparison of current and former animal product limiters. Appetite, 58, 1030-1036.

Hooley, D., \& Nobis, N. (2016). A Moral Argument for vegetarianism”. In A. Chignell, T. Cuneo, \& M. C. Halteman (Eds.), Philosophy comes to dinner. Routledge University Press.

Hursthouse, R. (2011). Virtue ethics and the treatment of animals. In R. G. Frey \& T. L. Beauchamp (Eds.), The oxford handbook of animal ethics. Oxford University Press.

Janssen, M., et al. (2016). Motives of consumers following a vegan diet and their attitudes towards animal agriculture. Appetite, 105(1), 643-651.

Key, Timothy, Paul Appleby, and Magdalena Rosell (2006). "Health Effects of Vegetarians and Vegan Diets." Proceedings of the Nutritional Society. 65: 35-41

Karen, W. (2000). Ecofeminism. Rowman and Littlefield.

Kortetmäki, T., \& Oksanen, M. (Forthcoming). "Is There A Convincing Case for Climate Veganism?" Agriculture and Human Values.

Le, L. T., \& Sabaté, J. (2014). Beyond meatless, the health of vegan diets: Findings from the adventist cohorts. Nutrients., 6, 2131-2147.

MacClellan, J. (2013). Size matters: Animal size, contributory causation, and ethical vegetarianism. Journal of Animal Ethics., 3(1), 57-68.

Marlow, H., et al. (2009). Diet and the environment: Does what you eat matter? The American Journal of Clinical Nutrition. https://doi.org/10.3945/ajen.2009.26736Z

McCann, B. S., \& Bovbjerg, V. E. (2009). Promoting dietary change. In S. Shumaker, J. K. Ockene, \& K. A. Riekert (Eds.), The handbook of health behavior change (3rd ed.). Springer.

McEvoy, C., Temple, N., \& Woodside, J. (2012). Vegetarian diets, low meat diets, and health: A review. Public Health Nutrition., 15(12), 2287-2294.

McPherson, T. (2016). Why i am a vegan (and you should be one too). In A. Chignell, T. Cuneo, \& M. Halteman (Eds.), Philosophy comes to dinner. Routledge.

McPherson, T. (2018). The ethical basis for veganism”. In A. Barnhill, M. Budolfson, \& T. Doggett (Eds.), Oxford handbook of food ethics. Oxford University Press.

Nestle, M. (2007). Food politics. University of California Press.

Nussbaum, M. (2006). Frontiers of justice. Harvard University Press.

Palmer, C. (2010). Animal ethics in context. Columbia University Press. 
Perrine, T. (2020). Consequentialism, animal ethics, and the value of valuing. Journal of Applied Philosophy, 37(3), 485-501.

Pimentel, D., et al. (2005). Environmental, energetic, and economic comparisons of organic and conventional farming systems. BioScience, 55(7), 573-582.

Rachels, S. (2011). Vegetarianism. In R. G. Frey \& T. L. Beauchamp (Eds.), The oxford handbook of animal ethics. Oxford University Press.

Reijnders, L., \& Soret, S. (2003). Quantification of the environmental impact of different dietary protein choices. American Journal of Clinical Nutrition, 78, 664S-S668.

Roddy, G., Cowan, C., \& Hutchinson, G. (1996). Consumer attitudes and behaviors to organic foods in Ireland. Journal of International Consumer Marketing, 9(2), 41-63.

Rosenfeld, D., \& Janet Tomiyama, A. (2019). When vegetarians eat meat: Why vegetarians violate their diets and how they feel about doing so. Appetite, 143, 104417.

Ruby, M. (2012). Vegetarianism. A blossoming field of study. Appetite, 58, 141-150.

Scarborough, P., et al. (2014). Dietary greenhouse gas emissions of meat-eaters, fish-eaters, vegetarians, and vegans in the UK. Climate Change, 125, 179-192.

Singer, P. (1980). Utilitarianism and vegetarianism. Philosophy and Public Affairs, 9(4), 325-337.

Singer, P. (2002). Animal liberation. HarperCollins.

Singer, P. (2011). Practical ethics (3rd ed.). Cambridge University Press.

Tilman, D., \& Clark, M. (2014). Global diets link environmental sustainability and human health. Nature, 515, 518-532.

United States Department of Agriculture. (2017). "2017 Census of Agriculture: United States, Summary and State Data." Available Online: https://www.nass.usda.gov/Publications/AgCensus/ 2017/index.php

United States Department of Agriculture. (2018a). "Annual Statistics Summary: Livestock, Meat, Poultry, Grain, and Slaughter Data.” Available Online: https:/www.ams.usda.gov/market-news/ livestock-poultry-and-grain-historical-annual-summaries

United States Department of Agriculture. (2018b). “2018: Poultry Slaughter.” ISSN: 1949-1581 Available Online: https://usda.library.cornell.edu/concern/publications/3197xm04j?locale=en

United States Department of Agriculture. (2018c). “2018: Chickens and Eggs.” ISSN: 1948-9064. Available Online: https://www.nass.usda.gov/Publications/index.php

Publisher's Note Springer Nature remains neutral with regard to jurisdictional claims in published maps and institutional affiliations. 